\title{
Hostland and Reception in Esther David's Book of Esther, Book of Rachel and Shalom India Housing Society
}

\author{
Ms Doyir Ete ${ }^{1}$, Dr Sravani Biswas ${ }^{2}$ \\ ${ }^{1}$ Asst Professor, Dept of English, RGU, Arunachal Pradesh,( Research Scholar) EFL, Tezpur University, Assam \\ ${ }^{2}$ Associate Professor, EFL, Tezpur University
}

*Corresponding Author: Ms Doyir Ete, Asst Professor, Dept of English, RGU, Arunachal Pradesh, (Research Scholar) EFL, Tezpur University, Assam

\begin{abstract}
Stereotyping of the Jews has been a common phenomenon in the West and Europe which has been reflected in major canonical texts like The Merchant of Venice, The Jew of Malta, Ivanhoe and Oliver Twist. However in India, their experience has been to a great extent positive. They were free to live according to their own volition and contribute to the economy of the nation. This paper will address questions like; how were the Indian Jews received in the sub-continent? Were they received with favour or were they perceived as threat by their neighbours? How much of the interface that took place influenced by the difference/similarities in their cultural, religious and other ways of life?The primary texts include Book of Esther, Book of Rachel and Shalom India Housing Society(SIHS) by prominent Indian Jewish writer Esther David who is also the recipient of the Sahitya Akademy for English literature 2010. Locating the Bene Israel within a large multicultural setting like India is one of her primary concerns. A very important question in this regard is the definition of a nation for a minority community and what does nationalism mean to them? The paper addresses all these issues as it is observed in the novels of the writer.
\end{abstract}

Keywords: Nation, Nationalism, Minority community, Hostland, Reception, Ambivalence.

Methodology: The research paper draws its methodology from the postcolonial school of thought on Nation and Identity. Theories on Nation and Nationalism by Benedict Anderson, Partha Chaterjee and Homi Bhbha have been used to study and analyze the selected novels.

\section{INTRODUCTION}

Being a multicultural country, India houses a large spectrum of communities which are racially, religiously and linguistically diverse. The focus has been very less in the public domain about the nation's engagement with the minority communities like the Parsis, Indian-Chinese, Jains, SyrianChristians and Indian Jews. Indian English Literature as a canon needs to foreground the writings from such minority groups and explore the dynamics involved in their identity constructions within the nation. Narration of the Bene Israel Jews and their experience in India has been vividly documented in the writings of Indian-Jewish writer Esther David. Her work is a blend of biography, history and culture foregrounding a hybridized Indian-Jewish ethos. As immigrants the complex relationship of the minority community with the nation is problematized in her fictional and nonfictional works. Her work is also concerned with the diasporic space that her community occupies in the state of India. As an emerging voice she works to create space and recognition for representations from the margins.

Esther David(b.1945) is the daughter of well known animal lover, philanthropist and Padmashree Reuben David(1912-1989).She grew up in the midst of animals and birds rescued and adopted by her father along with the intricate Jewish rituals and practice that was a part of her family. Her childhood and her family background molded her vision of India, her insights into the complex position of her community as well as her own identity as an Indian-Jew. Through the years Esther has achieved honor and recognition as a sculptor, artist, author and art critic. She was awarded the prestigious Sahitya Akademi for English literature in the year 2010. Thematically, her works are varied, dealing with subjects ranging from identity crisis, ambivalence, hybridity, historical and political questions and diaspora. There are three distinct groups of Jews in India that arrived at different periods. They are the Cochin Jews, Baghdadi Jews and the Bene Israel. To quote Shalva Weil "The Largest of India's 
Jewish communities, though minute by Indian standards is the Bene Israel -literally meaning "Children of Israel"(11).In discussing the distinct situation of the Bene Israel, Anderson's statement on nation, that "It is imagined because the members of even the smallest nations will never know most of their fellow -members, meet them, or even hear of them ,yet in the minds of each lives the image of their communion"(6) is relevant in two major observations ;first the sense of communion that the Bene Israel shared with Jews in the rest of the world and secondly the role of print and media which played a significant role in creating awareness of the Indian Jews particularly the Bene Israel to the existence of a larger Jewish community outside of India .The Bene Israel who had lived in complete seclusion in the Indian subcontinent for decades were untouched by events like the Holocaust and anti-Semitism. The dissemination of news through print and other media made them aware of these realities. The Jews in India never faced anti-Semitism and this fact is acknowledged by many important members of the community. But the knowledge that Jews in the rest of the world particularly Europe faced anti-Semitism made them aware of their own 'otherness' in India. Esther David states in Book Of Esther (2002)

"The Bene Israel Jews of India had suddenly become aware that they were connected to a larger Jewish community in Europe. More so, since they had been reading and listening to world news on the BBC about the gas chambers, concentration camps and the extermination of the six million Jews by Hitler"(David,2002:198).

Thus, it is the through print and other media like the BBC that news about the Holocaust and European anti-Semitism disseminated through which the Bene Israel became conscious of the other Jews and their suffering. Also, the rapid spread of education lead to the frequent exchange of literatures from the West and Europe into India and vice versa, which also familiarized the Indian Jews to the history and culture of Judaism outside of the sub-Continent. Thus, Anderson's print capitalism and its role in acquainting the Indian Jews to their position in India and with other Jews can be applied to a certain extent. Partha Chatterjee on the other hand, has questioned the Anderson model of nationalism stating that this was not applicable in a nation like India. Nationalism in India was a result of anti-colonial movement and the rise of the middle class intelligentsia during the British Raj. Since, majority of the people lived in the rural areas with very little or no education, print media had very less influence in the rise of nationalism in the country. He states that the middle class bourgeoisie in Bengal during the pre-independence years played very significant role in the rise of nationalism and national consciousness. This educated middle class recognized the distinction between the cultural/material attributes of the West and the spiritual wealth of the East. The distinction between the West and the East is carried forward to the domain of the public and private; the world and the home. This gave rise to what Chatterjee claims as the 'national culture'. Thus it is the spiritual domain that has been very significant in the rise of nationalism as a movement for India. This new brand of 'national culture' was hybrid in nature because it was at the same time both; traditional and modern. The role of the middle class in this new brand of national culture was not only limited to the Hindus or Muslims but also members of minority communities like the Indian Jews and Parsis. Of the communities that took the foremost advantage of missionary schools and schools opened by the British in India were the Parsis and the Indian Jewish community along with Anglo-Indians. Relating the spread of education in the family of Dandekar's in Book of Esther, the author notes "As the younger generation began going to English-medium missionary schools, the Dandekars started speaking in English. And when Joseph started to go to the American missionary school in Bombay, he learnt both English and Hebrew" (87).The missionary schooling would often mean that the Bene Israel gradually started speaking English at home like the Parsis and Anglo-Indians. The spread of education and exposure to the western society gradually gave rise to a new sophisticated class: the educated, elite and the intelligentsia .This 'new class' was both educated and spiritual. Esther David narrates how this educated middle class contributed to the freedom struggle as well as influenced the construction of the discourse of nationalism within the Bene Israel community. This echoes Bhabha's concept of hybridization particularly when a citizen occupies a subject position of the middle and the 'in-between'. The spread of education lead to reformation and progress in the Bene Israel community as a whole. This reformist attitude is also depicted by the author in the depiction of David Dandekar in Book Of Esther. He is one of the most fascinating and progressive character in the text. David is at once modern and traditional. Esther writes "His reformist zeal brought him into conflict with the Jewish community of Ahmadabad. David wanted to simplify rituals and make them easy to 
understand. But he faced opposition in the synagogue" (120). Though he was a reformist, David also taught the Hebrew prayers and regularly practiced the shabath prayers and other Jewish festivals. But it was his attitude to education that greatly benefited not only his family but the community. He was specially influenced by Vallabhbhai Patel and Mahatma Gandhi who were strong advocates of women's education. The author writes "David also became a great advocate of education" (120).He saw to it that his daughter Jerusha and son Menachem were well educated.

Partha Chatterjee also talks about the role of women in the nationalist movement. Many of the ideas shared by him can also be used to understand and examine women's role in the national movement from the perspective and involvement of the Bene Israel Jews. An important concern for nationalists was the question of the 'new woman'. In the domain of the private world, women had a very important role to play. They were the cultural bearers because it was through their private world of affairs; household chores, socializing, praying, dressing and children rearing that culture was maintained. This 'new women' also was hybridized because she had to be both; modern and traditional. Chatterjee writes "The "new woman" was to be modern, but she would also have to display the signs of national tradition and here fore would be essentially different from "Western" woman" (9).This 'new woman' had a very important role in the nationalist movement and in the cause of women's emancipation .In Book Of Esther Hannah weaves her own Khadi Sari for her wedding. Since women were not allowed to take active role in the public domain, this private act of defiance was also very significant in the way it influenced the other members of the family. This story is narrated with pride and love by the author. Esther David also portrays women who achieved recognition and eminence in different areas, specially medicine and teaching .Aunt Jerusha for instance is the first Bene Israel woman doctor and a reputed gynecologist. Bene Israel women also achieved reputation as school teacher at a time when Hindu society was reluctant to send their women to work outside the home. This is also affirmed by B J Israel in his book The Bene Israel of India. Naomi in Book Of Esther begins her professional life by working as a school teacher like many other Bene Israel women. Education and reformation in the community changed many of the attitudes and practice of the community. For instance, Esther narrates that Naomi and Joshua had one of the first civil marriages in the Bene Israel despite threats of excommunication from the community. As an educated class, the Dandekar family to which the writer herself belongs are exemplars of the Bene Israel in India.

For minority communities like the Bene Israel the question of nation and nationalism poses a special problem . Partha Chatterjee analogizes that the desire for independence and political unification by the Indian state was the same as the desire for the integration of the disparate communities and ethnicities from within the nation. This is particularly relevant when analyzing the status of different minority communities in India and their social, cultural and political desires and aspirations .India as a nation would be a great failure was predicted by many in the West and Europe. Chatterjee writes "One of the fundamental elements in the colonial conceptualization of India as a "different" society was the fixed belief that the population was a mélange of communities" (223).Therefore a nation with such disparate and diverse communities was doomed to fail. As we see, India was projected as inherently different because it did not fit into the European model of a nation, the basis of which should be the same lingual and racial stock. This was a biased way of looking at India from the prism of western standard and expectations. India has managed to grow and survive as a nation despite the disparate communities. But it has also to be acknowledged that the optimistic vision of the nation still requires great effort on the part of both; the state and the different communities within the state. The integration of the different ethnic, racial and minority communities is more than a political problem and it still continues to exude vehement debate and discourse about the nation.

Bhabha states in Location of Culture "...A just measure of global progress requires that we first evaluate how globalizing nations deal with 'the difference within'-the problems of diversity and redistribution of the local level, and the rights and representations of minorities in the regional domain" (XV). In other words, a nation's progress is also measured by how the state handles the minorities and other marginal groups within its territory. Thus, to understand the nuances of their experience in India, it is pertinent to understand the history and contact of the Bene Israel with other social groups of the nation. In Book Of Esther, Book Of Rachel and Shalom India Housing Society (SIHS), Esther David narrates how they were perceived and received by their Hindu and Muslim neighbors. In her novels, the experience of reception by the hostland i.e. India has been demonstrated 
as unproblematic and even welcoming but at the same time indifferent. Since the time of the biblical diaspora the Jews have been in exile, dispersed throughout the world, where they have lived and survived with various degrees of assimilation. But their experience in India stand out in its favorable hospitality and acceptance which has been testified time and again by many Indian Jews and even the writer .For instance, Esther writes in Book Of Esther,

"I had given myself many reasons to run away from India. Gradually, however, I realized that I had lived there as a Jew without fear. When I heard the stories of other immigrants and met the Holocaust survivors, I realized that in India we had never suffered because we were Jews. Perhaps it was the only country in the world where the Jews had never faced persecution" (372).

It is possible that the Hindu society viewed the Jews in India as a part of the social stratification that was practiced by them . Though the Bene Israel never considered themselves as a part of the Hindu social stratification. On the contrary, as B J Israel claims, the rigidity of the caste rules made it easier for the Bene Israel to preserve their identity, since it made it necessary for every caste to live within their own neighborhood. Yet, there are many instances where the Indian Jews particularly the Bene Israel had adapted many customs and practice of certain Hindu upper castes. For instance in Shalom India Housing Society (2007), Esther narrates a practice unique to the Bene Israel in matters of prayers and religious rituals. She writes "The Indian Bene Israel Jews are remarkable as they not only know what the prophet looks like but have taken the liberty of giving him a face, breaking all rules against idol worship"(1).The very issue of painting as a sin is also brought up in the story of Menashe in Book Of Esther. Abraham's younger son Menashe desires to become an artist. But Abraham is enraged. He says "...the Bene Israel did not make idols and images-that was the law"(44). What is observed here is that idolatory was considered sin in the community. But prophet Eliyahu Hannabi was an exception. Like their Hindu neighbours the Bene Israel worshipped the image of the prophet and kept his portrait at their homes. Eliyahu Hannabi is also compared to Lord Ganesha the Hindu deity. The author writes in Book Of Esther,

"All auspicious occasions started with Eliyahu Hannabi, in the same way that the Hindus started everything with the Ganesh sthapan. In the land of idols, the relic was image which helped the Bene Israel relate to their prophet"'(43).

Here, we see how the minority community assign the same significance and auspiciousness as the Hindu assign to lord Ganesha .Similarly, the author also writes in Book Of Rachel (2006) "Influenced by Indian ritual, Jews also believe that coconut is auspicious for new beginnings" (11).Many of these influences on the Bene Israel are the practices of the upper Hindu castes and these adaptations show how the community worked up its way into the hierarchy in the society. Esther David is very vocal about the Indianness of the Bene Israel in other spheres too. She narrates how the Bene Israel had adopted Marathi and Gujarati as their mother tongue .Book Of Rachel describes Rachel "As a rule she spoke in Marathi, the language she had known since her birth"(4). Further ,describing the neighborhood of Rachel the author writes, "They appreciated the fact that, although she was a Bene Israel Teli, she spoke Marathi with the right intonations, just like them, and also knew all the Maharashtrian customs, so much so that they often introduced her to their relatives as a Konkanasth Brahmin"(5). What is observed here is how language plays an important role in bringing Rachel closer to her Hindu neighbor's .It is interesting that they even acknowledged her as a Brahmin. The way she dressed in a sari and her fluency in the Marathi tongue made it easier for her to be accepted as one of them. The author writes "Rachel took pride in her new-found identity, which made her a part of their lives, not a stranger who belonged to a minority community."(5).Esther David's use of language also foregrounds the hybridized experience of the community. The language in her literary works is interspersed with the local and colloquial words spoken by the members of the community. The use of such words depict that Marathi had become an integral part of their life and also in religious rituals. In Book Of Rachel "Rachel remembered the lord by chanting Deva re Deva"( 8).In Book Of Esther the lord is referred to as "Parmeshwar"(21). They also referred to the Ten Commandments as the Daha Agnya, which is a literal translation into Marathi. Book of Esther also describes the mehendi ceremony as an important part of their marriage rituals which is also hybridized because the marriage ceremony is performed in the synagogue according to the Judaic customs. For instance Shebabeth in Book of Esther wears a mangalsutra. Another practice that became a part of 
their religious ritual was the singing of kirtans which was an influence of their Hindu neighbors. Many of the Marathi hymns of lord Krishna or lord Ganesha was translated into Hebrew, the names of gods was replaced with Moses in these hymns. For instance the author describes "...It was a Marathi bhajan kirtan which he changes into a Jewish song" (59). The influence on the ethnic cuisine and attire of the Bene Israel also show influence of the local community. Joshua in Book of Esther points out "Look at my wife. She wears a sari and she is no less a Jew than the women at the synagogue, My mother and grandmother wore nine -yard saris, with heavy anklets ,toe rings, armlets, waist belts and enormous nose rings but they all observed the Jewish rituals"( 369). These lines show the anxiety of Joshua who has to balance the Indianness along with their Jewishness. For minorities, assimilation and adaptation were means of survival under threats of homogenization and exclusiveness. Different attitudes during different periods towards the Bene Israel also give us some insight into the way the Indian society reciprocated to this community. For instance Esther David narrates in Book of Esther that the Bene Israel finds mention in the Puranas and they also share a common story of origin with the Chitpavan Brahmin. She writes "It is mentioned in the Puranas that while Parshuram circled the earth to exterminate the Kshatriyas and give more power to the Brahmins, he had seen fourteen corpses on the Konkan coast. The bodies were burnt and charred. They appeared to be foreigners. He realised that they belonged to an ancient race. Parshuram brought them back to life by chanting some mantras. These were supposed to be the Bene Israel. It is surprising that the Chitpavan Brahmins have a similar story! Perhaps we adopted a similar story so that we would find acceptance in the communities around us"( 30$)$. The need to be identified as an ancient race of the nation depicts how the narratives of the community traversed from an imagined past to the present day of consolidated identity. In a sense, they imagine themselves into the mythology of a nation in a bid to authenticate their history along with that of the nation. The relationship between the Muslim neighbors and the Bene Israel has been described by the author as cordial and cooperative at best. The shared affinities in terms of certain customs like: circumcision, monotheism and burial practice allowed the two communities to coexist with each other. One particular affiliation was their shared food habit. The strict adherence to the dietary laws as prescribed in the Shema was a unique feature of the Bene Israel that distinguished them from their Hindu neighbors and brought them closer to their Musilm neighbors. In Shalom India Housing Society, Esther narrates how in absence of Kosher meat, Jews sometimes bought Halal meat from Muslim vendors. But this relationship is tested at times of communal violence or conflicting situations. For example, the Godhra violence is the crux and also the binding force of the all the stories in Shalom India Housing Society. She writes "During the riots some of them saw an angry mob armed with spears stripping a young boy to see if he was circumcised. He was burnt alive'. The Jews had been terrified, as they were also circumcised"(9).So they decide to build a housing society that will house only Jews, so that their separate identity maybe maintained. It is inevitable that they share many similarities with other minor communities like the Parsis and Muslims, as such they may be mistaken for some of them and targeted. They feared "...what if their men were mistaken for Muslims because of a missing foreskin?" (3).Thus selfsegregation and self-ghettoization as measures of self-protection are forced upon them particularly during times of violence where minorities become vulnerable to victimization. As the author writes they were compelled to "move from the predominantly muslim moholla to safer part of the city"(9).

The Bene Israel has been described by B J Israel as the most Indianised group among the Indian Jews not only in terms of assimilation of cultural practice but in physical features too! In all aspects the Bene Israel were assimilated almost entirely into the ways of life of their Hindu and Muslim neighbours. This similarity became a major contention for the group whose authenticity as pure Jews was questioned both in India and in Israel. Tragically regarding their purity, the Bene Israel faced exclusion and segregation even from the other Jewish groups in India particularly the Bagdadi Jews. The practice of kala and gora Jews that existed among the Bagdadi Jews and the Bene Israel throw interesting light on this controversy. Esther David has also been conscious of this racism and how it affected the community. In Book of Esther for instance, Esther narrates the story of Jerusha, who is offered marriage by her Professor Dr Ezra, a widower and a Bagdadi Jew. This opens up a world of confrontations between the two communities that acts as obstacles in their union. As an educated and secular person Dr Ezra represents the enlightened view of the writer herself. He refuses to accept the 
superiority of the Bagdadis and the Cochin Jews and rejects the supposed inferiority of the Bene Israel. He states "Let us forget everything and just accept that we are both Jews. That is more important than anything else. I do not understand why your father should have a problem with me" ( 135).But this prejudice is so ingrained in the members that, the meaning of gora and kala transcend its literal meaning of fair and dark pertaining to the skin color ,to mean many more things like; pure and impure, believer and non-believer, honest and dishonest, superior and inferior. When Dr Jerusha confides in her mother she warns,

"...If you marry this Dr Ezra sir of yours, nobody will accept your marriage. Neither the Baghdadis nor the Bene Israel. Your children will suffer. They will not find acceptance in either community, and will be considered unfit to enter the assembly of the Lord for seven generations. Don't get carried away by this man and his clever words. If you go against our wishes and marry this Bagdadi, you will bring the curse upon yourself"'(136).

This shows how the problem of true or false Jews permeated the social and public life of the communities extending even into the personal lives of its members. Individuals like Dr Jerusha and Dr Ezra, though highly educated are held prisoners of racial politics.

In a modern world the phenomena of transnationalism, globalization and migration have continuously impinged on the construction of identity and affiliation of individuals as well as groups. Thus, even for the Bene Israel, their identity is as much an influence of their multivalent, hybrid and diasporic position as it is a product of their history and culture. As Bhabha points out, identity construction is a continuous process, which is influenced by both; time and history. Thus the subjectivity of minorities like the Bene Israel is constructed by the influence of their ethnic as well as Indian identity.

\section{CONCLUSiON}

India is the only country where the Jews did not face any kind of religious persecution. Yet there is an underlying tension in many of Esther David's narrations which problematizes the happiness of the community in India. Questions arise whether this is a politics of happiness and whether behind the evocative narrative of an Indian-Jewish ethos there is a garb of insecurity and difference? In an increasingly global and transnational world, perspectives on these experiences are paramount for the mutual coexistence of different communities. The different responses of the hostland to this community through different ages and periods show that the Indian Jews in general and the Bene Israel in particular were received and accepted as a part of the Indian society which already housed a multitude of communities. The response of the Hindu and Muslim communities to them was free from confrontations though a degree of distance and detachment existed primarily because of the difference in cultural and religious practice. The most outstanding feature of the Jewish experience in India has been the total absence of anti-Semitism which has been a hallmark in the entire history of the Jews in the world. If at all, there was any form of victimization or violence towards the Jews in India, it was due to different factors like communal violence, religious prejudice and majoritarian politics, which were local issues, but one can say with confidence that these were not the product of anti-Semitism as it existed in Europe. It is true that the community has been vulnerable at times of social unrest and violence, which has lead many of them to question their future in the country. But at the same time, their long history of coexistence has been acknowledged as unique. The community has flourished under the favorable and receptive society of India, and many of them have achieved distinctions in many different spheres. Their unique experience in India has inspired writers from the community like Nissim Ezekiel, Sophie Judah and Esther David who have enriched the literary scene through their originality and creativity.

\section{REFERENCES}

[1] Anderson, Benedict. Imagined Communities:Reflections on the Oriigin and Spread of Nationalism. London: Verso, 2006.

[2] Bhaba, Homi. The Location of Culture. New York: Routledge, 1994,2014. English.

[3] Chatterjee, Partha. "Whose Imagined Community?". Omnibus, Oxford University Press, 1999.Print

[4] David, Esther. Book of Esther. Penguin Books India, 2002.Print.

- Book of Rachel. Penguin Books India,2006.Print

- Shalom India Housing Society. Women Unlimited, New Delhi, 2007.Print 
Hostland and Reception in Esther David's Book of Esther, Book of Rachel and Shalom India Housing Society

[5] Israel,Benjamin J.The Bene Israel Of India. Orient Longman,1984,Print.

[6] Weil Shalva, ed. India's Jewish Heritage. Mumbai: Marg Publications, 2006. Print.

Citation: Ms Doyir Ete, Dr Sravani Biswas "Hostland and Reception in Esther David's Book of Esther, Book of Rachel and Shalom India Housing Society" International Journal on Studies in English Language and Literature (IJSELL), vol 5, no. 12, 2017, pp. 49-55. doi:http://dx.doi.org/10.20431/2347-3134.0511005.

Copyright: (C) 2017 Authors. This is an open-access article distributed under the terms of the Creative Commons Attribution License, which permits unrestricted use, distribution, and reproduction in any medium, provided the original author and source are credited. 